\title{
Cognitive Assessment of Knowledge Consolidation in a Course on the Diagnostic Evaluation of Learning Disorders in Psychology Students
}

\author{
Guadalupe Elizabeth Morales-Martinez \\ National Autonomous University of Mexico, Mexico City, Mexico \\ https://orcid.org/0000-0002-4662-229X \\ Yanko Norberto Mezquita-Hoyos \\ Autonomous University of Yucatán, Yucatan, Mexico \\ https://orcid.org/0000-0001-6305-7440
}

Maria Isolde Hedlefs-Aguilar

FIME, Nuevo Leon Autonomous University, Monterrey, Nuevo Leon, Mexico https://orcid.org/0000-0003-1138-9835

Miriam Sanchez-Monroy

Tecnologico Nacional de Mexico-Instituto Tecnologico de Merida, Yucatan, Mexico https://orcid.org/0000-0001-5263-1216

\begin{abstract}
This study explored the cognitive changes to long-term memory as a result of academic learning in 43 Psychology undergraduate students (91\% female and 9\% male). The participants carried out a conceptual definition task based on the Natural Semantic Networks technique. They defined ten target concepts related to the diagnostic evaluation of learning disorders using verbs, nouns, or adjectives as definers. After, students weighed the quality of each definer through a ten-point scale. The higher the score, the greater the conceptual relationship between the definer and the target. The data of this study (the schema behavior) was subjected to a computational simulation. Finally, the participants carried out a lexical decision task based on the semantic priming paradigm, they read pairs of words that may or may not be related to the measured knowledge schema. The task was to judge whether the second word in each pair was spelled correctly or incorrectly. The results indicated an increase in the level of conceptual accessibility derived from learning. In addition, the participants accessed their knowledge schema, first through general nodes and then retrieved through the more specific nodes. The neurocomputational activation pattern suggested that learning experiences changed the meaning of concepts for each participant along the course. At the end of the course, the students seemed to reach a
\end{abstract}


schematic consolidation. The diagnosis of these cognitive characteristics through the formation of academic schemas can provide learning opportunities closer to each student's cognitive profile to increase the effectiveness of instruction.

Keywords: knowledge schema; chronometric learning assessment; Natural Semantic Networks; semantic priming paradigm; psychology students

\section{Introduction}

Assessment is a central and intrinsic link between learning and teaching; it provides opportunities for students to certify the knowledge they acquire in classes. Furthermore, learning assessment offers information about the effectiveness of the educational strategies used by teachers (Lambert \& Lines, 2000, Pesare et al., 2015; Wiliam, 2011). In the same way that online and face-toface education requires the implementation of new teaching and learning methods, learning assessments also require new strategies to measure learning and the effects of teaching. The creation and implementation of new means of evaluation are not an easy task since the evaluation activity has many purposes, many ways to be approached (Wragg, 2001), and has a wide range of applications and levels of operation (Corrigan et al., 2013); therefore, its effects can be widely varied (Wragg, 2001).

Generating a favorable impact of assessment on instruction and learning is not a simple matter. Heitink et al. (2016) mentioned that although the primary aim of a learning assessment is to amplify student learning, there are factors related to the nature of the assessment, the teacher, the student, and the context that affect its implementation in daily classroom activities. Furthermore, Arieli-Attali (2013) mentioned that the available assessment instruments provide information on specific moments. It is not possible to obtain a complete picture of the continuous progress of the learning process; consequently, the results obtained from these evaluations can improve a narrow spectrum of aspects of the learning and teaching processes.

In addition to the theoretical and applied complexity of learning assessment, the incorporation of new technology into its design and application is a challenge. The current paradigms of learning assessment and its instruments require a consideration of the demands of the 21st-century classroom. Incorporating technology to design assessment instruments will reduce the gap between didactic and instructional innovation and the modernization of learning assessment tools. In this regard, Gomez et al. (2011) highlighted the importance of considering new social demands, scientific, and technological advances in innovation, and instrumentation research for the evaluation of learning. Pesare et al. (2015) mentioned that an improved digital assessment of learning must consider the use of authentic learning through digital means, involving the use of discrete measurement instruments to provide data for computer analysis. It should also provide information to improve learning and instructional strategies. 
The above points to the need to build digital learning assessment systems that go beyond the encapsulation of existing measurement instruments. In this regard, cognitive psychology offers a wide range of measurement tools to help build these new evaluation systems. For example, the Chronometric Constructive Cognitive Learning Evaluation Model or C3-LEM (Lopez et al., 2014; Morales-Martinez, 2020; Morales-Martinez et al., 2015, 2017; MoralesMartinez \& Lopez-Ramirez, 2016; Morales-Martinez, Lopez-Perez et al., 2020; Morales-Martinez, Hedlefs-Aguilar et al., 2021; Morales-Martinez, TrejoQuintana et al., 2021), is an initiative that proposes the combined use of research techniques and digital tools in cognitive science to explore the mechanisms of knowledge acquisition and to promote student learning. This model is based on the principles and laws of human cognitive function from the Human Information Processing (HIP) and Parallel Distributed Processing (PDP) approach.

HIP is a cognitive approach that proposes that cognitive processes, including learning, follow a sequential processing model. From this theoretical position, the mind of a student is seen as a symbolic processor capable of storing information in cognitive structures. The student manipulates this information to form new meanings of their external and internal environment. On the other hand, the PDP proposes that the human brain processes information in a parallel and distributed way; there is no sequence to the processing. Instead, cognitive processes can occur simultaneously and happen in different neural units at the same time. From the PDP, a student's mind would act as a processor capable of simultaneously performing multiple cognitive operations, and their learning is not limited to a single brain structure. Students build and re-build their schemas every moment, and these cognitive structures are flexible, self-organized, and emerging. The laws and principles coming from HIP and PDP are helpful to enhance our understanding of how students build knowledge structures through learning experiences.

\section{Cognitive principles of knowledge construction and consolidation}

From the perspective of cognitive psychology, students are animated cognitive systems that actively construct their internal world. According to Wiley and Jee $(2011 / 2010)$, study of this inner world requires a determination of the characteristics of the information processing in the mind of a student. In this regard, the C3-LEM explores learning regarding the principles and assumptions of the cognitive function of students (e.g., active cognitive beings, goal-directed beings, schema builders, susceptibility to the influence of the internal and external environment) (Figure 1). 


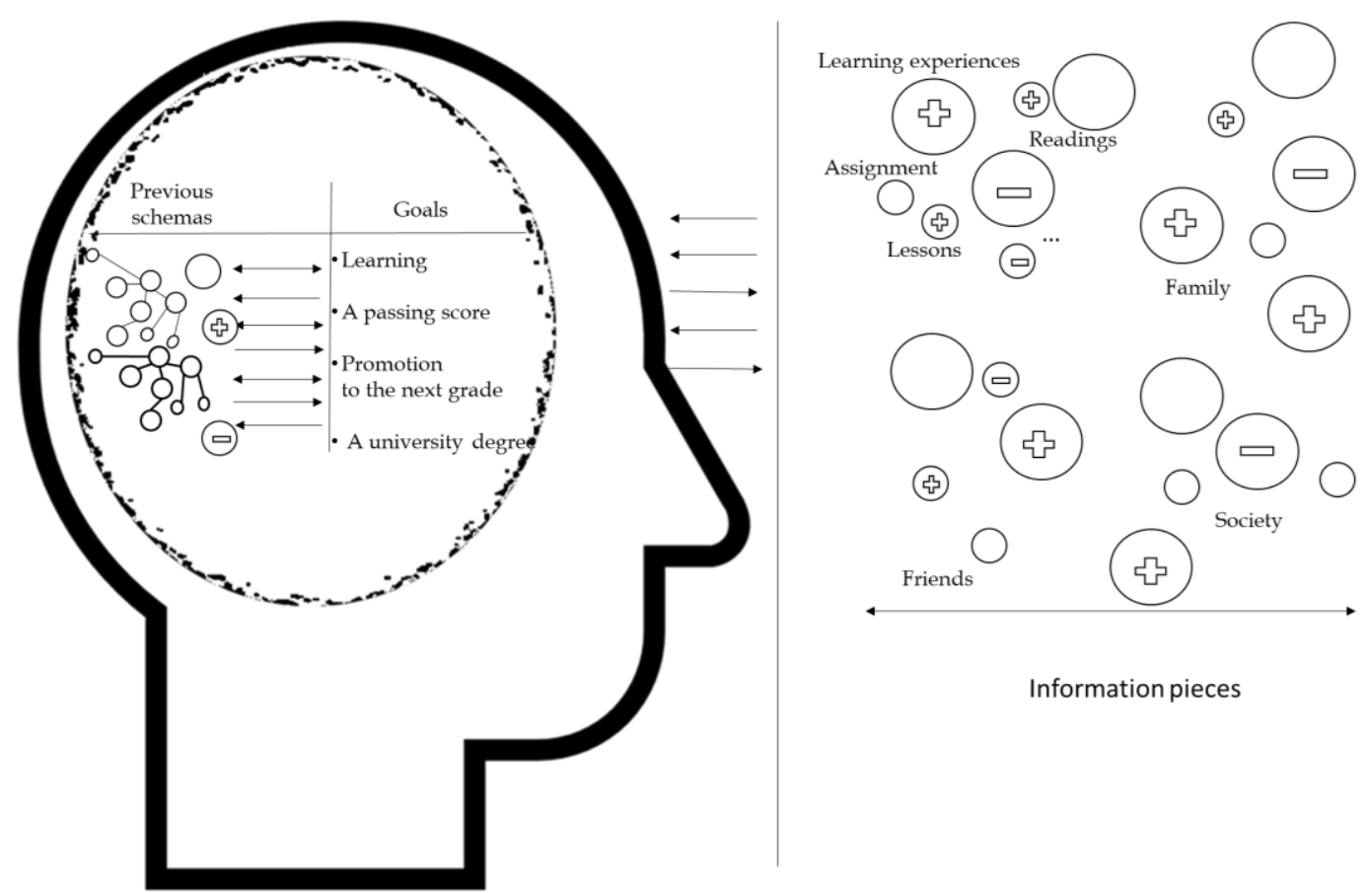

Figure 1. The student as an active cognitive agent and the influences to form academic knowledge schemas.

In general, the C3-LEM takes the following into consideration:

1. Human thoughts and actions are goal-directed (Bransford et al., 2000). Students are cognitively autonomous and goal-driven beings. These goals influence information selection, coding, storage, and use of information by the student.

2. Human beings can create mental representations and modify them based on their daily experiences (Morales-Martinez, 2020). Students create mental representations of the knowledge they learn through academic learning experiences.

3. The information acquired by a person through their experiences is stored in memory though mental structures called knowledge schemas (Seel, 2012; Rumelhart et al., 1986). Students form knowledge schemas from the information they learn in academic courses.

4. Schemas contribute to different cognitive functions such as integrating information, regulating attention, and making inferences (Seel, 2012). Previous and new knowledge schemas influence the students' processing of academic information.

5. Schemas are not faithful copies of world phenomena but result from the cognitive processing of information through the interaction of an active cognitive agent with the world (Rumelhart et al., 1986). Students build their knowledge schemas based on the meaning they give to the information they learn in class.

6. Schemas have different levels of complexity and abstraction (Rumelhart et al. 1986). The complexity of a student's schema and their level of abstraction change as the student advances in their academic development; they have a greater number of learning experiences. 
7. Information can be stored in different formats (declarative, procedural, eidetic) within memory structures (Surprenant \& Neath, 2009). Then, students can store and represent information in as many formats as there are types of information.

8. Declarative knowledge is stored in human memory in natural semantic networks (Busselle, 2017). Then, students represent declarative information in the form of semantic networks.

9. Semantic networks have information nodes and relational links between nodes (Busselle, 2017). The semantic networks of the students must contain conceptual nodes and semantic relationships based on the knowledge schema learned in the course. Schematic relationships should dominate in the semantic networks formed in the student's memory throughout an academic year.

10.Knowledge schemas are dynamic structures; they are enactive and selforganized phenomena of the mind (Rumelhart et al., 1986). Students' cognitive structures are flexible phenomena that emerge under specific learning contexts and are self-organized differently depending on the experiences and learning goals that elicit them.

11.Schematic flexibility and stability depend on the level of development of the cognitive structure (see Schwarting, 2003). Knowledge schemas in their initial phase tend to be more flexible and less stable; they have greater schematic permeability than when schemas are already established or when the student has a higher level of academic development.

12. The learning process always starts from an existing point (Bransford et al., 2000; Eggen \& Schellenberg, 2010; Surprenant \& Neath, 2009). Thus, students use their previous structures of knowledge as the cognitive basis for new learning.

13. Memory is inherently constructive; it uses the information it encodes, the keys to retrieve information, and previous memories to generate a response to a key (Surprenant \& Neath, 2009). Then, students require the presentation of effective information keys to activate their memory and reconstruct schemas from information already contained in their memory.

14. All mental processes take up time according to their nature and complexity (Jensen, 2006). The time taken for students to retrieve, recognize, or manipulate information provides information about their learning process. For example, if students learn a knowledge schema, the presentation of conceptual keys related to that schema will produce a semantic priming effect in the recognition time of the information belonging to this schema (schematic priming).

Considering the above principles and assumptions, the study of the formation of cognitive structures derived from academic learning involves the exploration of the effect of academic learning experiences on the content, organization, structure, dynamics, and time patterns of the students' knowledge schemas.

\section{Cognitive measurement of the knowledge schemas consolidation}

The concept of memory has different meanings within cognitive psychology. Memory can result from changes in the brain as a response to learning; it is the 
hypothetical and unobservable product that must be inferred from cognitive performance. On the other hand, it can be seen as a retention process and the recovery of information (Crowder, 2015). From both points of view, research on the ways students encode, store, and retrieve information from their memories is essential to develop more effective learning assessments and teaching and learning strategies. In this regard, the C3-LEM is a valuable tool in the exploration and establishment of comparison parameters on the processes of assimilation and accommodation of academic knowledge (declarative, procedural, and eidetic) in the mental structures of the student (MoralesMartinez, Angeles-Castellanos et al., 2020; Morales-Martinez, Hedlefs-Aguilar et al., 2021).

In general, the application of the C3-LEM involves two evaluation phases (Figure 2). During the constructive cognitive assessment, the evaluator uses a mental representation technique to explore how students construct their knowledge structures: the Natural Semantic Networks (NSN) technique proposed by Figueroa et al. (1976). The NSNs use keys (target concepts) that allow students to retrieve the information stored in their memory (nodes, relationships between nodes, configuration of nodes, and the relationships between them) to reconstruct their knowledge schema on the topics evaluated. Lopez and Theios (1992) described the NSN procedure as a conceptual definition task that requires the participants to define target concepts related to a knowledge schema, using different types of words (adjectives, nouns, verbs) as definers. Then they weighed each of these words in terms of their quality in this context.

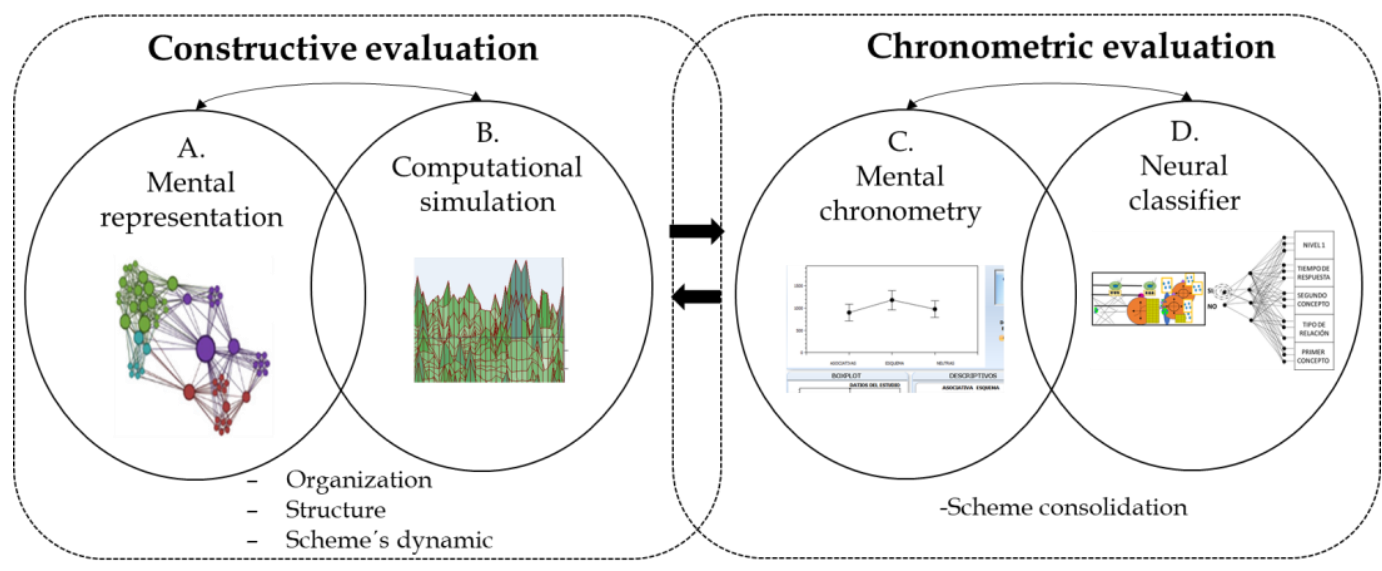

Figure 2: The two phases and components of the C3-LEM.

Note: From "Cognitive e-tools for diagnosing the state of medical knowledge in students enrolled for a second time in an anatomy course," by Morales-Martinez, AngelesCastellanos et al., 2020, International Journal of Learning, Teaching and Educational Research, 19(9), p. 346 (https:/ / doi.org/10.26803/ijlter.19.9.18). Copyright 2020 by the authors and IJLTER.ORG.

Subsequently, the researchers carried out a computational simulation on the data from the NSN study. From the connectionist point of view, mental processes, including learning, can be modeled through interconnected artificial neural networks. Neural networks are composed of the units and the connection 
weights (Shultz, 2011/2010). The C3-LEM contemplates the analysis of the organization and schematic dynamics by extracting the connectivity weights between the conceptual units or nodes that constitute the semantic network learned by the students. The calculation of the connectivity weights matrix is carried out with the SASO procedure or Semantic Analyzer of the Schematic Organization from Lopez and Theios (1992). This procedure includes the estimation of the probability of co-occurrence of the definers through the NSN and the construction of a co-occurrence matrix that finally feeds a neural network of satisfaction of restrictions. The objective is the observation of the activation dynamics of the nodes that make up the knowledge schema.

The second phase, the chronometric evaluation, comprises the application of mental chronometry studies and a neural network to classify the temporal patterns observed in these studies. Conventionally, the C3-LEM uses the semantic priming paradigm to observe if the stored information was consolidated in memory in terms of the knowledge schema. The semantic priming paradigm proposes that information recognition can be affected by the information that precedes it (Morales-Martinez, Hedlefs-Aguilar et al., 2021). Usually, the paradigm includes the application of lexical decision tasks, which consists of the presentation of word pairs, which may have a semantic relationship (associative, schematic, or categorical) or may not be related. The participants read the first word (prime) after reading the last word (target) and decide if the last word is well written or badly written. In this type of task, the improvement in time or recognition accuracy of a piece of information (target) resulting from the presentation of other information (prime) is known as the "priming effect" (McNamara, 2005). When this effect is presented in a schematic pair of words, where a schematic word primes the recognition of its schematic target, the effect is called "schemata priming" (Lopez, 1996; Lopez \& Theios, 1992).

The schematic priming effect is presented when students store the information learned in a course then structure and organize it into a knowledge schema (Trujillo et al., 2019). Hence, for the C3-LEM, the temporal patterns obtained from recognizing words with a schematic relationship are central to determining if the students incorporated, organized, structured, and consolidated the course information to their memory.

The results of the C3-LEM studies indicate that students enter academic courses with prior knowledge structures (Morales-Martinez, Trejo-Quintana et al., 2021). This previous knowledge allows students to select and sift through new information based on previous experience and individual levels of academic development. In addition, these previous knowledge structures allow the student to identify and store the necessary and sufficient aspects to complement, complete, modify, and build new knowledge structures, or destroy existing cognitive knowledge structures. In this regard, Schwarting (2003) mentioned that mental structures are fragile at the initial stage of construction and become stronger or weaker over time. In line with this idea, Morales-Martinez, GarciaTorres et al. (2021) asserted that the knowledge schemas of beginners may allow 
for greater permeability to new information since their structures are less formed and therefore exhibit a greater cognitive malleability compared to the knowledge schemas of advanced students in a course.

Regardless of the student's academic development level and the stability and flexibility of their knowledge schemas, these cognitive structures constantly change with exposure to learning experiences. Gonzalez et al. (2018) mentioned that computational simulations provide information on these conceptual changes due to academic learning that cannot be observed through the visual tools of mental representation conventionally used in the classroom as mind maps or tree diagrams. In general, the results of C3-LEM connectionist studies on academic learning indicate that activated concepts can coerce information implicitly related to the activated concept (Gonzalez et al., 2018; MoralesMartinez, Angeles-Castellanos et al., 2020). They also pointed out that there are changes in the connectivity pattern related to the meaning that students give to their knowledge after being exposed to different learning experiences (MoralesMartinez, Hedlefs-Aguilar et al., 2021).

On the other hand, the chronometric studies of learning with the C3-LEM shows that the time taken to retrieve information from memory when performing definition tasks in the NSN differs before and after the course (MoralesMartinez, Hedlefs-Aguilar et al., 2021). The schematic information recognition times significantly decrease towards the end of the course compared to the recognition times initially obtained. This occurs only when academic learning affects the level of conceptual accessibility of the learned knowledge schema (Trujillo et al., 2019). This phenomenon of schematic priming occurs only when the student has formed and solidly stored a schema in their long-term memory from the information reviewed in the course. On the other hand, when students store information but do not construct the schema, they seem to have difficulties in the accurate retrieval and recognition of the schematic information (MoralesMartinez, Angeles-Castellanos et al., 2020).

The C3-LEM studies have provided information on the cognitive characteristics of knowledge acquisition in different academic domains such as moral development (Gonzales et al., 2013), cognitive psychology (Morales-Martinez, Lopez-Perez et al. 2020), anatomy (Morales-Martinez, Angeles-Castellanos et al., 2020), biology (Urdiales-Ibarra et al., 2018), and engineering (Morales-Martinez et al., 2018). However, there is still no explanation of the cognitive processes and mechanisms involved with the education on topics such as learning disorders. This work explored the consolidation of knowledge related to the diagnostic evaluation of learning disorders in psychology students.

Since it was observed in previous studies that between the start and end of an academic year, students have different access times between the conceptual nodes of the NSN (Morales-Martinez, Hedlefs-Aguilar et al., 2021), this study explored whether these differences in Inter-Response Time (IRT) were present between the common conceptual nodes of the initial and final NSN of the evaluated course. The authors hypothesized that if the students organize the 
prior knowledge in their memory more efficiently, then the conceptual nodes common from this initial knowledge at the end of the course would present a shorter appearance time in the final NSN.

On the other hand, in the computational simulation, the definers with high and low IRT were activated in the initial and final NSN to explore the co-activation patterns given the access time of the explored definers. A final objective was to determine the consolidation level of the information stored in the student's memory in the form of a knowledge schema. Some studies with the C3-LEM indicated that students who do not organize or structure information properly tend to exhibit slower recognition times for words pairs with a schematic relationship (Morales-Martínez, Angeles-Castellanos et al., 2020; MoralesMartinez et al., 2018). In this study, it was expected that if the students consolidated the information in an organized knowledge schema, their recognition times in the experimental trials with pairs of schematic words would decrease significantly towards the end of the course due to their learning experiences. In a certain sense, semantic priming in the concepts' accessibility is expected given the learning obtained during the course.

\section{Method}

\subsection{Study objective}

The present study measured the declarative knowledge learning in psychology students at the beginning and end of a course regarding the diagnostic evaluation of learning disorders. With this purpose in mind, the authors applied a mental representation technique, a computational simulation, and an experimental study to determine the cognitive characteristics in the content, organization, structure, dynamics, and temporal patterns of the evaluated knowledge schema in the students' memory.

\subsection{Study design}

According to the C3-LEM, the authors designed a mental representation study based on the NSN technique, which involved a random presentation of the 10 most relevant conceptual nodes of the evaluated knowledge schema. This study used a conceptual definition task on these conceptual nodes using verbs, nouns, adjectives, and pronouns as definers, weighing each definer in terms of the quality of their semantic relationship with the relevant conceptual node. The authors then performed a computational simulation on the data from this first study and designed an experimental study based on the semantic priming paradigm.

\subsection{Participants}

A group of 43 undergraduate psychology students (91\% female and 9\% male) participated in this study. All participants were enrolled in a course on the diagnostic evaluation of learning disorders taught in the 5th semester of psychology in a Mexican university. The mean age of participants was 19.7 years old $(S D=1.30)$. All participants were volunteers and received extra credits for their participation. 


\subsection{Instruments and materials}

The design of the NSN study required the presentation of 10 conceptual stimuli (development, psychomotor, learning, dyslalia, dyslexia, dyscalculia, attention deficit, evaluation, diagnosis, and report). The semantic priming study required the creation of 45 experimental trials by using 45 facilitator-target pairs (e.g., development-psychosocial, deficit- hyperactive). The Protocol for the Collection of Target Concepts and Central and Deferred Definers served to select the NSN target concepts and the prime-target words used as inputs in this study (Morales-Martinez, 2015). This protocol is a guide to determine the concepts that encompassed the entire conceptual content of the evaluated knowledge schema and the most relevant concepts to the schema. The authors used EVCOG (Cognitive Evaluator) software to design, apply, capture, and analyze the NSN and semantic priming study data (Morales-Martinez and Lopez-Ramirez, 2018 a, $\mathrm{b}, \mathrm{c}, \mathrm{d}, \mathrm{e}, \mathrm{f}, \mathrm{g} \mathrm{h}$ ). In addition, this software allowed for computational simulation on the NSN data.

\subsection{Procedure}

The study was developed through three phases: consent, constructive evaluation (NSN), and computational simulation, and chronometric evaluation (semantic priming). During the first phase, the participants received information about the study objectives and were informed of their benefits and rights. Subsequently, the participants gave informed verbal consent and began the study's second phase, which included the application of a conceptual definition task based on the NSN technique. Ten target concepts were presented on the computer screen. Each target remained on the screen for a minute. Participants read and defined each target concept with verbs, nouns, adjectives, and pronouns, then rated the quality of each definer based on a ten-point scale, where small numbers indicated that the definer was a little related to the target concept and larger numbers indicated the definer was more closely related to the target concept. The authors then ran a computational simulation with the data from the NSN study. To do this, they fed the EVCOG with the SASO matrix (see data analysis), which is a conceptual co-occurrence matrix. The software allowed the extraction of the schematic co-activation pattern from the activated concepts.

Finally, the participants performed a lexical decision task based on the semantic priming paradigm. Participants would silently read word pairs and decide whether the last word of each pair was spelled correctly. First, the participants saw a dot appear for 500 milliseconds (ms) on the screen to help draw the participant's attention to where the first word (prime) would appear. The prime remained for $250 \mathrm{~ms}$, long enough for the participant to read the prime silently. This word disappeared, and in its place, a second word was presented indefinitely until the participant decided whether it was written correctly.

\section{Data analysis}

First, to observe the pattern of cognitive access to information, visual analysis was made regarding the pattern of the IRT obtained at the beginning and end of the course from NSN. The authors determined whether the differences observed between these patterns were significant through a student's t-test for dependent 
samples. Subsequently, a computational simulation contributed to observing the higher and lower IRT definers' conceptual co-activation patterns. The simulation followed the procedure described in Morales-Martinez, Hedlefs-Aguilar et al. (2021). In general, the EVCOG software was fed with the SASO conceptual cooccurrence matrix (Lopez \& Theios, 1992), and finally, some relevant concepts were activated. The concepts with the highest and lowest IRTs were selected to observe their co-activation patterns. Finally, the authors performed mixed ANOVA on the data from the semantic priming study.

\section{Results}

\subsection{Analysis of the IRT of NSN}

The authors analyzed the temporal pattern of recovery of the definers in the NSN to determine if it changed due to the learning process. Figure 3 shows that toward the end of the course, there were a greater number of definers recovered in less time. To the left of the $X$ axis, the reader can observe a withdrawal in the appearance of the concepts. The definers with the highest $M$ values are not necessarily the first to be accessed.

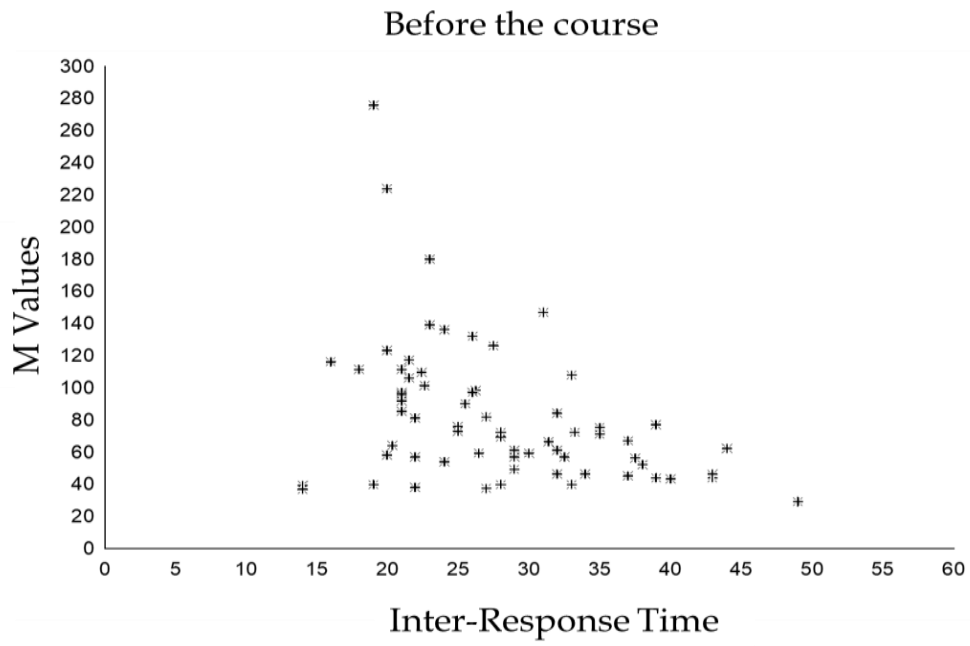

After the course

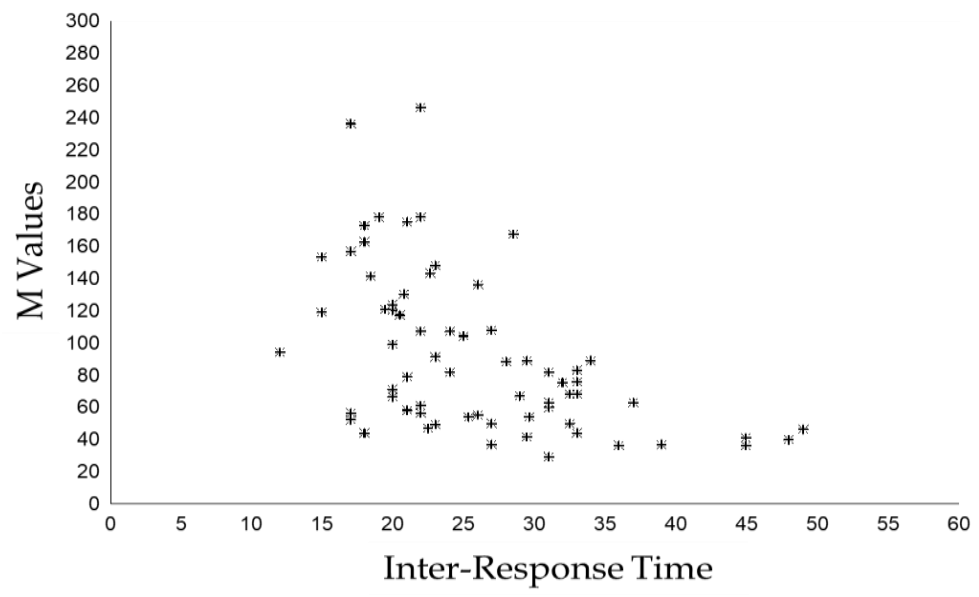

Figure 3. The relationship between the IRTs and the $M$ values for the definers of the NSN obtained before and after the course. 
To determine whether the change in IRT patterns was statistically significant, the authors compared the IRTs by including in the analysis only the access times of the common definers obtained before and after the course. Figure 4 shows a significant difference between the IRT obtained before the course $(\mathrm{M}=27.3$, SD $=$ 7.38) and those obtained after the course $(\mathrm{M}=24.8, \mathrm{SD}=8.04)(\mathrm{t}(43)=2.05, \mathrm{p}=$ $.04)$.

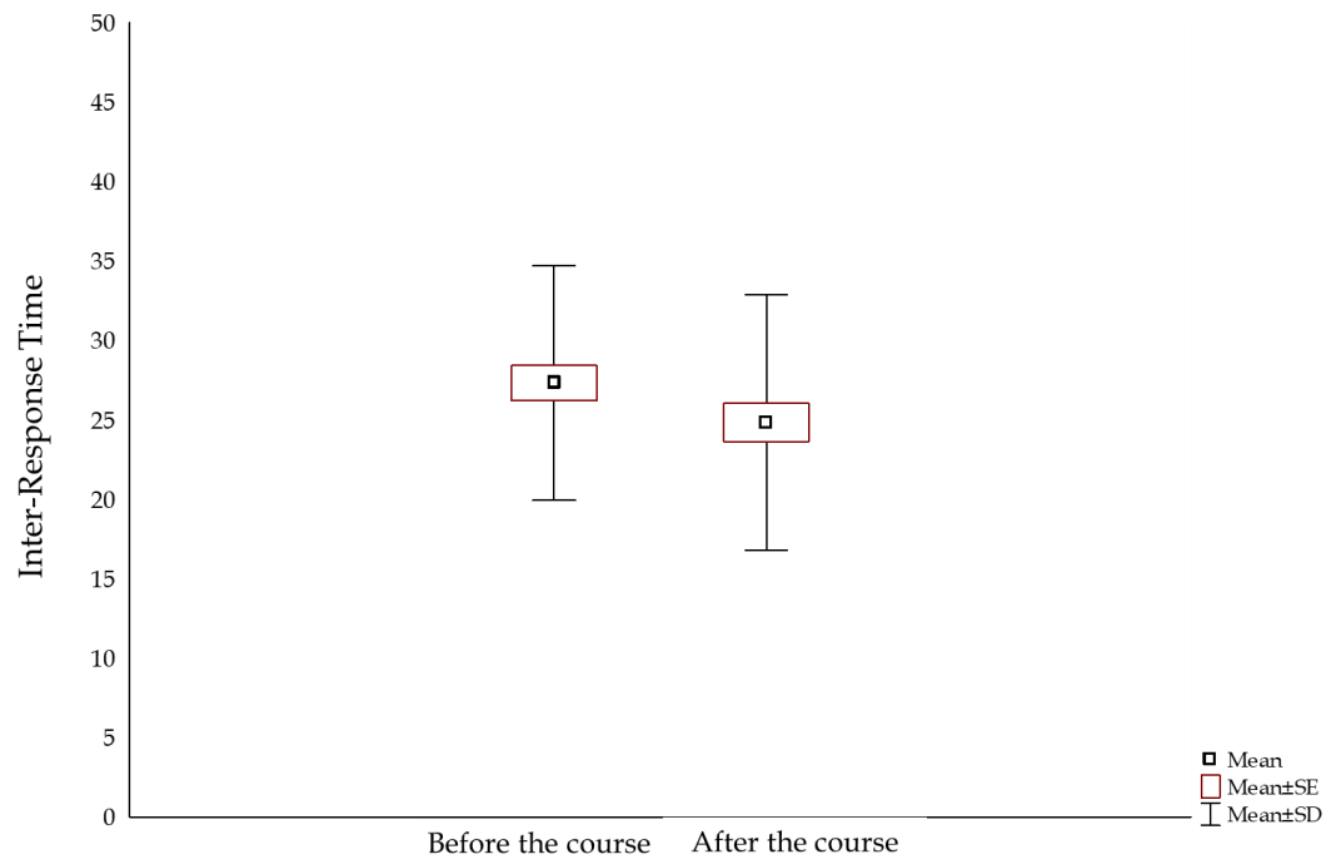

Figure 4. Temporal performance to retrieve information nodes before and after course.

Furthermore, the trends in the appearance times of common definers through both measurement phases indicated that access to information seems to be more organized towards the end of the course (Figure 5). At the beginning of the course, information retrieval does not appear to follow a trend. In contrast, at the end of the course, the data suggests that students began to retrieve information through general concepts (e.g., growth, evolution, motor skills, mathematics). After, they accessed nodes more closely related to the evaluated schema (e.g., movement, evaluation, hyperactivity, diagnosis, development, tests, attention). Moreover, as the IRTs progress, the recovery of more general definers occurs (e.g., school, learning, children, knowing), and specific definers (e.g., pronunciation) continue to appear but in smaller numbers. Additionally, a correlation analysis between the M values and IRT for the NSN indicates a negative relationship between these two indicators at the beginning $(\mathrm{r}-.48)$ and the end of the course ( $\mathrm{r}-.56)$. 

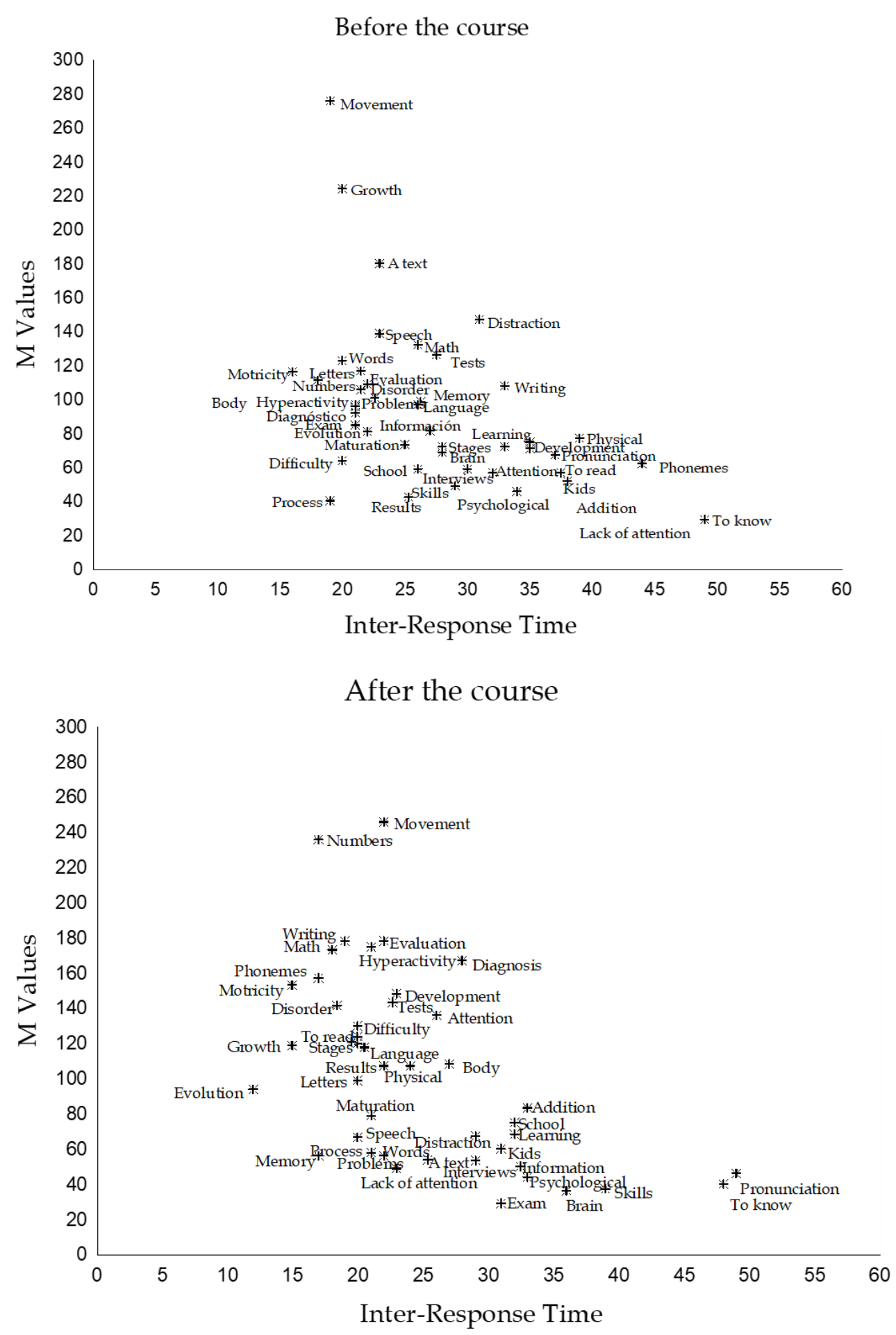

Figure 5. The relationship between the IRTs and the $M$ values for the common definers of the NSN obtained before and after the course

\subsection{Computational simulation}

A computational simulation was carried out on the definers with higher (knowledge, phoneme) and lower (motor, process) IRTs. The goal was to observe if there were changes in the co-activation pattern towards the end of the course related to the appearance time. The computational simulation results indicated 
that the concepts with lower IRTs seem to activate different meanings at the course's beginning and end (Figure 6). For example, the concept of motor skills at the beginning of the course activated concepts related to child development, while at the end, it was oriented more to a perspective of learning disorders. The process also presented a change in its meaning. Initially, it was associated with learning development, while no definer was activated at the end of the course.

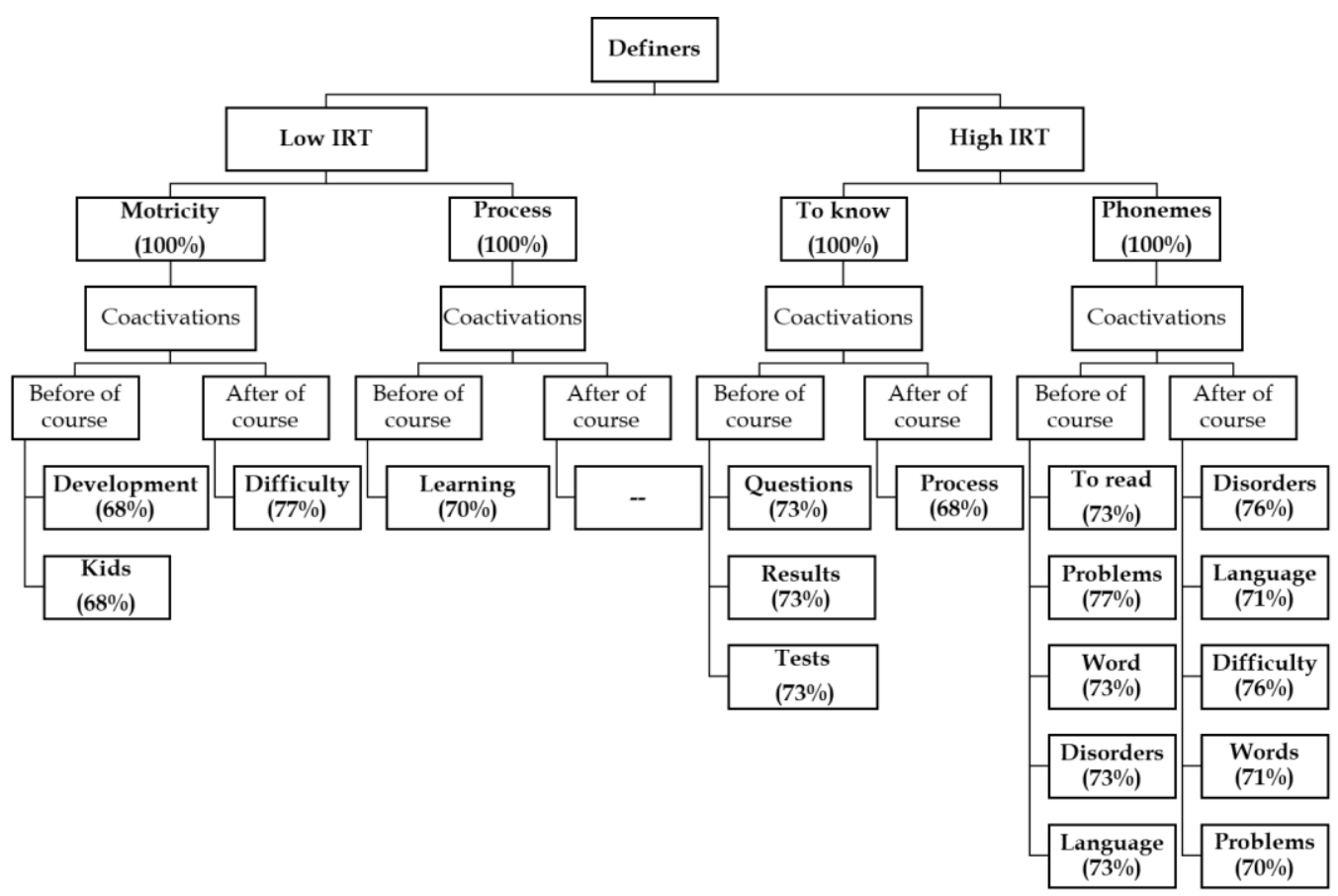

Figure 6. The pattern of co-activations of four selected concepts on their IRTs.

\subsection{Semantic priming results}

A mixed ANOVA was carried out on the data from the semantic priming study considering a design of 2 (course time beginning vs. course time end) $\times 3$ (associative semantic relationship vs. schematic semantic relationship vs. unrelated pairs of words) (Table 1). The level of significance was $p \leq .01$. This analysis considered only the reaction times of the trials that were answered correctly by 41 of the 43 participants. For inclusion in the statistical analysis, each participant's data had to meet the following criteria: obtain at least $70 \%$ correct answers in the experimental conditions analyzed and have participated in the study at the beginning and end of the course.

Table 1: ANOVA of repeated measures

\begin{tabular}{llllllll}
\hline \multirow{2}{*}{ Factor } & \multicolumn{2}{c}{ Effect } & \multicolumn{2}{c}{ Error } & $\boldsymbol{F}$ & $\boldsymbol{p}$ & $\boldsymbol{\eta}_{\boldsymbol{p}}{ }^{2}$ \\
\cline { 2 - 6 } & $\boldsymbol{d f}$ & \multicolumn{1}{c}{$\boldsymbol{M S}$} & $\boldsymbol{d f}$ & \multicolumn{1}{c}{$\boldsymbol{M S}$} & & & \\
\hline Course time (T) & 1 & 1765808.796 & 80 & 122845.511 & $14.374^{*}$ & .000 & .15 \\
Semantic relation (S) & 2 & 2357768.991 & 160 & 14502.390 & $162.577^{*}$ & .000 & .67 \\
$\mathrm{~T}{ }^{*} \mathrm{~S}$ & 2 & 24354.065 & 160 & 14502.390 & 1.679 & .189 & .02 \\
\hline
\end{tabular}

Note: $\mathrm{N}=41 ; \mathrm{ANOVA}=$ analysis of variance; $\mathrm{df}=$ degree of freedom; $\mathrm{MS}=$ mean square; $\eta_{\mathrm{p}}{ }^{2}=$ partial eta squared. ${ }^{*} p \leq .001$ 
Both factors (course time and semantic relationship) presented a statistically significant effect. No interaction effect was observed between the factors. The authors conducted post hoc comparisons to explore the differences among the reaction time means obtained before and after the course. The Tukey HSD test pointed out that the mean reaction time for the recognition of schematic words decreased significantly at the end of the course $(p=.001)$, and these recognition times were significantly different from those of the other two experimental conditions ( $p$ <.001). However, the reaction times in recognition of neutral words also showed a significant decrease at the end of the course $(p<.001)$, and these times were significantly different from those obtained in associative pairs $(\mathrm{p}=.006)$.

\section{Discussion}

One of the most relevant challenges in education is the ability to understand the academic learning to improve it. Learning assessment is a strategy to monitor the process of acquiring knowledge and skills throughout a course to implement more efficient and effective learning and teaching strategies. However, today, learning assessments are focused on the measurement of academic performance; this separates the evaluation of the learning process and the evaluation of learning (Gibbs, 2006). In addition, Arieli-Attali (2013) mentions that most assessment tools offer a sectional view of the learning process. Further, there is a gap between technological advances in instruction and the technology incorporation to innovate the methods of learning evaluation. One way to approach these challenges is to implement the inclusion of cognitive technology for the assessment of learning.

In this study, the C3-LEM framed the learning assessment; this model uses cognitive technology to measure the progress of declarative knowledge acquisition. From cognitive psychology, the learning of declarative knowledge involves the formation, incorporation, or elimination of information nodes in knowledge structures or the formation, strengthening, weakening, or disappearance of the semantic relationships between the conceptual nodes. Also, academic learning also involves changes in the activation patterns of the conceptual nodes, the temporal access patterns, the recognition and processing of the conceptual nodes, and the knowledge schema's use. Concerning chronometric measurement, the results obtained in the NSN and semantic priming studies suggest IRT and Reaction Times were effective indicators to determine the consolidation and dynamics of the knowledge schema in each student's long-term memory.

In general, the results obtained indicate that the students presented essential changes in the access to the conceptual nodes during the NSN task. At the end of the course, there is a negative bias (towards the left) in the conceptual access times (Figure 3). The decrease in IRT was statistically significant for the common concepts between the initial and final network (Figure 4). These results are similar to those reported in Morales-Martinez and Santos-Alcantara (2015) as they observed this same retraction of the IRT; however, these authors did not discuss the reasons for this time pattern. In this regard, the present authors 
assume that this finding supports the following hypothesis: if students more efficiently organize the conceptual nodes of their semantic network, access to common nodes will be faster in the final NSN.

Regarding the relationship between the semantic relevance weight of the definers and their time of appearance, Morales-Martinez, Hedlefs-Aguilar et al. (2021) pointed out that concepts with high $\mathrm{M}$ values tend to appear between 20 and 40 seconds between the third and fifth position of access, and hypothesized that, given its relevance, this pattern could be related to a question of cognitive load. In the present study, concepts with the highest $M$ value generally appear from the second position in terms of access; however, there are also concepts with $M$ values that may appear very late in the NSN. The correlation analysis between the $M$ values and the IRTs of both initial and final NSN indicate a significant negative relationship between these indicators: the higher the $M$ value, the shorter the IRT. Therefore, the higher the $M$ value, the more accessible a concept is, although this does not necessarily mean they appear in the first position.

Relating to the IRT, Morales-Martinez, Hedlefs-Aguilar et al. (2021) did not reported the whole conceptual distribution, consequently it was impossible to observe if there was a pattern linked to the schema in the conceptual access. Here, IRT distribution and the concepts distribution were presented; these distributions indicated that the participants seem to access the concepts at the end of the course in order terms of generality. As shown in Figure 5, the students first accessed the more general concepts of the knowledge schema and then accessed the more specific concepts. These findings match those observed by Morales-Martínez, Trejo-Quintana et al. (2021); they reported that after learning course contents, students tend to recover new, more specific concepts, although general concepts still linger in their memory. This finding suggests that at the end of a course, the students' conceptual access temporal curve recovered general aspects combined with very specific definers of the schema. If this is a common conceptual accessibility pattern, it was not possible to determine with a single study. A greater number of explorations on the conceptual appearance patterns must be carried out to determine if there is a typical pattern in retrieving academic information.

The change from a general content schema to one with specific content indicates a meaning change because of academic learning. In the present study, participants reorganized definers and reweighted them at the end of the course (Figure 5). Similarly, Morales-Martínez, Hedlefs-Aguilar et al. (2021) reported a cognitive restructuration in M and IRT distribution of definers in the students' memory as a learning product. Therefore, changes in M values and IRT can be related to the changes in knowledge schema configuration and the cognitive accessibility of concepts. Then, these indicators account for the new meanings of course content that emerge from learning experiences. In fact, at the end of the course, higher $M$ values were given to specific definers. This result shows that there was a conceptual reappraisal. 
The computational simulation results showed a different activation pattern from the beginning to the end of the course. These changes seem to be associated with a change in the meaning that students gave to the knowledge schema they learned in class. These results agree with those reported by Lopez-Ramirez et al. (2015) in different domains of knowledge (information systems, customer service, and music). Also, in a course of moral development, Gonzalez et al. (2018) reported a change in activation patterns resulting from learning experiences. Although this study founded implicit knowledge activation, they did not provide a discussion about the meaning of these changes in knowledge schema activity. In this regard, Morales-Martinez, Angeles-Castellanos et al. (2020) reported that activation of implicit knowledge suggests an associative relation between knowledge schemas in other domains and the evaluated schema. In this work, the present authors suppose that the activation of prior knowledge could reflect the conceptual development level of the student. For example, at the beginning of the course in this study, activation of motricity (one of the concepts with a high $\mathrm{M}$ value) co-activated definers related more to typical development (development and children), while at the end of the course, this same concept co-activated definers related to learning disabilities (difficulty). This kind of cognitive change suggests that students' minds shifted from general schema of human development to a schema more related to learning disorders. Then students achieved a more specialized knowledge on this topic.

An interesting aspect of the co-activation pattern is that there were concepts that did not modify their activation pattern as phonemes that co-activated almost the same concepts at the beginning and end of the course. This finding suggests that some concepts retained the same meaning with which they entered the course. These concepts may have less flexibility to change since they are concepts seen more frequently throughout academic training or are more concrete. The activation between abstract and concrete concepts, concepts reviewed more frequently, and concepts that are relatively new to students could be manipulated in new experiments. These findings are in accordance with what was stated by Schwarting (2003) about the flexibility and stability of the schemas depending on the level of consolidation of the cognitive structure. In this same line, Morales-Martinez, Garcia-Torres et al. (2021) suggested that the less information available and the less consolidated the schema is in memory, the more the schema permeability is increased. Therefore, this study indicates that the level of permeability and flexibility of the knowledge schema can vary through its different components or conceptual nodes. In the same cognitive structure, there may be variations in the configurational and organizational stability of the schema.

The data from the semantic priming study indicate that there was a significant decrease in the recognition time for the schematic targets, although this effect was also present for the associative and unrelated word pairs. In an ideal study, the schematic priming effect should de present only in schematic word pairs, as shown by Trujillo et al. (2019), who founded a clear schematic priming effect in a moral development course. However, the semantic priming effects found in the present study were more similar to those reported by Morales-Martinez, 
Hedlefs-Aguilar et al. (2021) in engineering students. They reported a significant decrease in the target recognition time in all pairs of words; however, this decrease was greater for the targets of the pairs of schematic words. The present authors propose several factors that can produce these results; for example, if the experiment in this study included a smaller number of experimental trials than the studies carried out in adolescents (moral development), it is possible the presence of a practice effect in the performance of the participants. Another possibility is that the younger the age of the students, the more careful they are to follow instructions.

In general, the present study's data indicated that the access and recognition time of the schematic words varies from the beginning to the end of the course, which suggests that the learning experiences affected the cognitive structures of students. These results provide evidence for the existence of the schematic priming phenomenon as reported by Lopez (1996) and Lopez and Theios (1992). However, the inclusion of stricter controls regarding the application of the studies is essential; for example, inclusion of a more significant number of experimental trials could reduce the variances and the effect of practice. Also, inclusion of comparison groups or controls can help to provide more information on the experimental effects.

\section{Conclusion}

In this study, the authors used the C3-LEM to measure the level of information consolidation in the memory of students. The study results show that the time indicators (IRT and reaction time) are helpful for exploration of the patterns of assimilation, consolidation, and recovery of the information learned during an academic year. The results suggest that the levels of conceptual accessibility seem to change in light of the students' learning experiences. These experiences also seem to influence the conformation and consolidation of the schema. After learning the course information, the improvement of the recognition times of the schematic words and the change of the neuro-computational activation pattern can indicate new meanings from the course contents.

It is necessary to consider that the scope of this study is limited by the small sample size and the lack of a control and comparison group. Hence, to determine the theoretical, methodological, and applied scopes of the cognitive assessment learning techniques suggested in this work, it is important to include new experimental controls, expand the sample size, and apply the C3-LEM to other knowledge domains in different education levels. Diversification of the application of this learning assessment model will provide more evidence on the usefulness of this type of approach in the educational field and will allow for an increased collection of more information on how cognitive properties of academic learning vary through human development and different disciplines. The cognitive characterization of individual and group learning will open opportunities to design learning strategies that cognitively model the processes of the acquisition of knowledge and skills of students. For example, information on the temporal cognitive characteristics of the students' knowledge schemas can promote each student's metacognitive skills (assessment as learning) and 
provide valuable information to increase the effectiveness of instruction and learning strategies (assessment for learning).

\section{References}

Arieli-Attali, M. (2013, October 20-25). Formative assessment with cognition in mind: The cognitively based assessment of, for and as learning (CBALTM) research initiative at educational testing service [Paper presentation]. Proceeding of the 39th annual conference on Educational Assessment 2.0: Technology in Educational Assessment, Tel Aviv, Israel. https://iaea.info/conference-proceedings/39thannual-conference-

2013/?search=Formative+assessment+with+cognition+in+mind $\% 3 \mathrm{~A}+\mathrm{The}+\operatorname{cogn}$ itively+based+assessment+of $\% 2 \mathrm{C}+$ for+and+as+learning

Bransford, J. D., Brown, A. L., \& Cocking, R. R. (Eds.). (2000). How people learn: Brain, mind, experience, and school. National Academy Press. https://www.nap.edu/catalog/9853/how-people-learn-brain-mind-experienceand-school-expanded-edition

Busselle, R. (2017). Schema theory and mental models. In P. Rossler, C. Hoffner \& L Zoonen (Eds.), The international encyclopedia of media effects (pp.1-8). Wiley Online Library.

Corrigan, D., Buntting, C., Jones, A., \& Gunstone, R. (2013). Valuing assessment in science education: An introductory framework. In D. Corrigan, R. Gunstone \& A. Jones (Eds.), Valuing assessment in science education: Pedagogy, curriculum, policy (pp. 1-9). Springer.

Crowder, R. G. (2015). Principles of learning and memory: Classic edition. Psychology Press.

Eggen, P., \& Schellenberg, S. (2010). Human memory and the new science of learning. In M. S. Khine \& I. Saleh (Eds.), New science of learning: Cognition, computers and collaboration in education (pp. 79-107). Springer.

Figueroa, J. G., Gonzalez, E. G., \& Solis, V. M. (1976). An approach to the problem of meaning: semantic networks. Journal of Psycholinguistic Research, 5(2), 107-115. https://doi.org/10.1007/BF01067252

Gibbs, G. (2006). How assessment frames student learning. In C. Bryan \& K. Clegg (Eds.), Innovative assessment in higher education (pp. 23-26). Routledge.

Gomez, R. M. A., Rodríguez, G. G., \& Ibarra, M. S. (2011). Caracterización de la eEvaluación orientada al e-Aprendizaje [Characterization of e-Assessment oriented to e-Learning]. In G. G. Rodríguez \& S. M. S. Ibarra (Eds.), E-Evaluation orientada al e-aprendizaje estratégico en educación superior [E-Evaluation oriented to strategic e-learning in higher education] (pp. 33-56). Narcea Ediciones.

Gonzales, C. J., Lopez, E. O., \& Morales, G. E. (2013). Evaluating moral schemata learning. International Journal of Advances in Psychology (IJAP), 2(2), 130-136. https://archive.org/details/IJAP047

Gonzalez, C. J., Lopez, E. O., \& Morales, G. E. (2018, May 26-28). Self-organized schemata behavior and meaning formation to evaluate e-learning [Paper presentation]. The International Conference on Distance Education and Learning. Beijing, China. https://doi.org/10.1145/3231848.3231877

Heitink, M. C., Van der Kleij, F. M., Veldkamp, B. P., Schildkamp, K., \& Kippers, W. B. (2016). A systematic review of prerequisites for implementing assessment for learning in classroom practice. Educational Research Review, 17, 50-62. https://doi.org/10.1016/j.edurev.2015.12.002

Jensen, A. R. (2006). Clocking the mind: Mental chronometry and individual differences. Elsevier. 
Lambert, D., \& Lines, D. (2000). Understanding assessment: Purposes, perceptions, practice. Routledge.

Lopez, R. E. O. (1996). Schematically related word recognition (Publication No. 9613356) [Doctoral dissertation, University of Wisconsin-Madison]. ProQuest Dissertations and Theses Global.

Lopez, E. O., Morales, G. E., Hedlefs, M. I., \& Gonzalez, C. J. (2014). New empirical directions to evaluate online learning. International Journal of Advances in Psychology, 3(2), 40-47. https:// doi.org/10.14355\&ijap.2014.0302.03

Lopez-Ramirez, E. O. Morales-Martinez, G. E. Hedlefs-Aguilar, M. I., Gonzalez-Trujillo, C. J., \& Moreno-Meza, A. P. (2015). Nuevas direcciones empíricas en la investigación e innovación de tecnología educativa para la evaluación del aprendizaje en línea: una aproximación conexionista [New empirical directions in educational technology research and innovation for the evaluation of online learning: a connectionist approach]. Ciencia UANL, 18(71), 52-64.

Lopez, E. O., \& Theios, J. (1992). Semantic analyzer of schemata organization (SASO). Behavior Research Methods, Instruments, $\mathcal{E}$ Computers, 24(2), 277-285. https://doi.org/10.3758/BF03203508

McNamara, T. P. (2005). Semantic priming: Perspectives from memory and word recognition. Psychology Press.

Morales-Martinez, G. E. (2015). Protocolo para la recolección de conceptos objetivo y definidores centrales y diferidos (PRECODECD): un sistema de codificación de conceptos extraídos de las redes semánticas naturales [Protocol for the collection of objective concepts and central and deferred definers (PRECODECD): A coding system for concepts extracted from natural semantic networks] [Unpublished manuscript]. Institute of Research on the University and Education, National Autonomous University of Mexico.

Morales-Martinez, G. E. (2020). Sistema de evaluación cognitiva constructiva cronométrica del aprendizaje en linea y presencial [Online and face to face learning's constructivechronometric cognitive assessment system] [Manuscript submitted for publication]. Institute of Research on the University and Education, National Autonomous University of Mexico.

Morales-Martinez, G. E., Angeles-Castellanos, A. M., Ibarra-Ramirez, V. H., \& ManceraRangel, M. I. (2020). Cognitive e-tools for diagnosing the state of medical knowledge in students enrolled for a second time in an anatomy course. International Journal of Learning, Teaching and Educational Research, 19(9), 341-362. https://doi.org/10.26803/ijlter.19.9.18

Morales-Martinez, G. E., Hedlefs-Aguilar, M. I., Trejo-Quintana, J., Mezquita-Hoyos, Y. N., \& Sanchez-Monroy, M. (2021). Chronometric constructive cognitive learning evaluation model: Measuring the consolidation of the human cognition schema in psychology students' memory. International Journal of Learning, Teaching and Educational Research, 20(5), 56-72. https://doi.org/10.26803/ijlter.20.5.4

Morales-Martinez, G. E., \& Lopez-Ramirez, E. O. (2016). Cognitive responsive eassessment of constructive e-learning. Journal of e-Learning and Knowledge Society (Je-LKS), 12(4), 39-49. http://www.je-lks.org/ojs/index.php/JeLKS_EN/article/view/1187

Morales-Martinez, G. E., \& Lopez-Ramirez, E. O. (2018a). EVCOG Modulo 1. Configurador RSN [EVCOG Module 1. NSN Configurator] (Version 1.1.) [Computer software]. Registro Publico del Derecho de Autor. 03-2018-111311554300-01

Morales-Martinez, G. E., \& Lopez-Ramirez, E. O. (2018b). EVCOG Modulo 2. Capturador RSN [EVCOG Module 2. NSN Data storage] (Version 1.1.) [Computer software]. Registro Publico del Derecho de Autor. 03-2018-1113115235001 
Morales-Martinez, G. E., \& Lopez-Ramirez, E. O. (2018c). EVCOG Modulo 3. Editor RSN [EVCOG Module 3. NSN Editor] (Version 1.1.) [Computer software]. Registro Publico del Derecho de Autor. 03-2018-1113115235001

Morales-Martinez, G. E., \& Lopez-Ramirez, E. O. (2018d). EVCOG Modulo 4. Análisis RSN [EVCOG Module 4. NSN Analysis] (Version 1.1.) [Computer software]. Registro Publico del Derecho de Autor. 03-2018-1113115235001

Morales-Martinez, G. E., \& Lopez-Ramirez, E. O. (2018e). EVCOG Modulo 5. Simulador del esquema [EVCOG Module 5. Schema simulator] (Version 1.1.) [Computer software]. Registro Publico del Derecho de Autor. 03-2018-112912551900-01

Morales-Martinez, G. E., \& Lopez-Ramirez, E. O. (2018f). EVCOG Modulo 6. Configurador FACSEM [EVCOG Module 6. FACSEM Configurator] (Version 1.1.) [Computer software]. Registro Publico del Derecho de Autor. 03-2018-111311402900-01

Morales-Martinez, G. E., \& Lopez-Ramirez, E. O. (2018g). EVCOG Modulo 7. Capturador FACSEM [EVCOG Module 7. Data storage] (Version 1.1.) [Computer software]. Registro Publico del Derecho de Autor. 03-2018-111311154200-01

Morales-Martinez, G. E., \& Lopez-Ramirez, E. O. (2018h). EVCOG Modulo 8. Analisis FACSEM [EVCOG Module 8. FACSEM Analysis] (Version 1.1.) [Computer software]. Registro Publico del Derecho de Autor. 03-2018-111311193400-01

Morales-Martinez, G. E., Lopez-Ramirez, E. O., Castro-Campos, C., Villarreal-Treviño, M. G., \& Gonzales-Trujillo, C. J. (2017). Cognitive analysis of meaning and acquired mental representations as an alternative measurement method technique to innovate e-assessment. European Journal of Educational Research, 6(4), 455-464. https://www.eu-jer.com/EU-JER_6_4_455_Morales-Martinez_etal.pdf

Morales-Martinez, G. E., Lopez-Ramirez, E. O., \& Lopez-Gonzalez, A. E. (2015). New approaches to e-cognitive assessment of e-learning. International Journal for eLearning Security (IJeLS), 5(2), 449-453. https://doi.org/10.20533/ijels.2046.4568.2015.0057

Morales-Martinez, G. E., Lopez-Perez, R. M., Garcia-Collantes, A., \& Lopez-Ramirez, E. O. (2020). Evaluación constructiva cronométrica para evaluar el aprendizaje en línea y presencial [Chronometric constructive assessment to assess online and face-to-face learning]. Tecnología, Ciencia y Educación, 15(1), 105-124. https://www.tecnologia-ciencia educacion.com/index.php/TCE/article/view/371

Morales-Martinez, G. E., Garcia-Torres, M., Castro-Gonzalez, M. C., \& Mezquita-Hoyos, Y. N. (2021). The measurement of knowledge construction in a course of diagnostic evaluation of learning disorders in psychology students. International Journal of Learning, Teaching and Educational Research, 20(8), 240-261. https://doi.org/10.26803/ijlter.20.8.15

Morales-Martinez, G. E., Lopez-Ramirez, E. O., \& Lopez-Gonzalez, A. E. (2015). New approaches to e-cognitive assessment of e-learning. International Journal for eLearning Security (IJeLS), 5(2), 449-453. https://doi.org/10.20533/ijels.2046.4568.2015.0057

Morales-Martinez, G. E., Mezquita-Hoyos, Y. N., Gonzalez-Trujillo, C. J., Lopez-Ramirez, E. O. \& Garcia-Duran, P. J. (2018). Formative e-assessment of schema acquisition in the human lexicon as a tool in adaptive online instruction. In R. Lopez-Ruíz (Ed.), From natural to artificial intelligence - algorithms and application (pp. 69-88). IntechOpen. https://www.intechopen.com/books/from-natural-to-artificialintelligence-algorithms-and-applications/formative-e-assessment-of-schemaacquisition-in-the-human-lexicon-as-a-tool-in-adaptive-online-instr 
Morales-Martinez, G. E., \& Santos-Alcantara, M. G. (2015). Alternative empirical directions to evaluate schemata organization and meaning. Advances in Social Sciences Research Journal, 2(9), 51-58. https:/ / doi.org/10.14738/assrj.29.1412

Morales-Martinez, G. E., Trejo-Quintana, J., Charles-Cavazos, D. J., Mezquita-Hoyos, Y. N., \& Sanchez-Monroy, M. (2021). Chronometric constructive cognitive learning evaluation model: Measuring the construction of the human cognition schema of psychology students. International Journal of Learning, Teaching and Educational Research, 20(2), 1-21. https://doi.org/10.26803/ijlter.20.2.1

Pesare, E., Roselli, T., Rossano, V., \& Di Bitonto, P. (2015). Digitally enhanced assessment in virtual learning environments. Journal of Visual Languages $\mathcal{E}$ Computing, 31, 252-259. https://doi.org/10.1016/j.jvlc.2015.10.021

Rumelhart, D., Smolensky, P., McClelland, J., \& Hinton, G. (1986). Schemata and sequential thought processes in PDP models. In J. McClelland, D. Rumelhart \& the PDP Research Group (Eds.), Parallel distributed processing: Explorations in the microstructure of cognition: Vol. 2. Psychological and biological models (pp. 7-57). MIT Press.

Schwarting, R. K. W. (2003). The principle of memory consolidation and its pharmacological modulation. In R. H. Kluwe, G. Lüer, \& F. Rösler (Eds.), Principles of learning and memory (pp. 137-153). Birkhäuser.

Seel, N. M. (2012). Schema (s). In N. M. Seel (Ed.), Encyclopedia of the Sciences of Learning (p.170). Springer Verlag. https://doi.org/ 10.1007 / 978-1-4419-1428-6_3

Shultz, T. R. (2011). Connectionism and learning. In V. G. Aukrust (Ed.), Learning and cognition in education (pp. 25-33). Elsevier. (Reprinted from International encyclopedia of education, pp. 476-484, by P. Peterson, E. Baker, \& B. McGaw, Eds., 2010, Elsevier Limited).

Surprenant, A. M., \& Neath, I. (2009). Principles of memory. Psychology Press.

Trujillo, C. J. G., Ramírez, E. O. L., \& Ibarra, M. E. U. (2019). Cognitive chronometric assessment of constructive knowledge: an empirical approach to support formative assessment. Journal of Physics: Conference Series, 1175 (1), 1-5. https://doi.org/10.1088/1742-6596/1175/1/012133

Urdiales-Ibarra, M. E., Lopez-Ramirez, E. O., Castro-Campos, C., Villarreal-Treviño, M. G., \& Carrillo-Colon, J. E. (2018). Biology schemata knowledge organization and meaning formation due to learning: a constructive-chronometric approach to concept mapping usability. Creative Education, 9(16), 2693-2706. https://doi.org/10.4236/ce.2018.916203

Wiley, J., \& Jee, B. D. (2011). Cognition: Overview and recent trends. In V. G. Aukrust (Ed.), Learning and cognition in education (pp. 3-8). Elsevier. (Reprinted from International encyclopedia of education, pp. 245-250, by P. Peterson, E. Baker \& B. McGaw, Eds., 2010, Elsevier Limited).

Wiliam, D. (2011). What is assessment for learning?. Studies in Educational Evaluation, 37(1), 3-14. https:/ / doi.org/10.1016/j.stueduc.2011.03.001

Wragg, E. C. (2001). Assessment and learning in the secondary school. Routledge. 